\title{
PAINTING HISTORY: Indigenous Observations and Depictions of the 'Other' in Northwestern Arnhem Land, Australia
}

\author{
Sally K. May ${ }^{1}$, Paul S.C. Taçon ${ }^{2}$, Daryl Wesley ${ }^{3}$ and Meg Travers ${ }^{1}$
}

\begin{abstract}
In this paper we focus on contact rock paintings from three sites in northwestern Arnhem Land, Australia. In doing so we highlight that such sites provide some of the only contemporary Indigenous accounts of cross-cultural encounters that took place across northern Australia through the last 500 years. Importantly, they have the potential to inform us about the ongoing relationships that existed between different parties. The lack of research on contact rock art is emphasised and the development of a large-scale project (of which this fieldwork is part) aimed at addressing this problem is outlined. Important new findings for contact rock art are presented, including evidence for 'traditional' protocols relating to rock art continuing long after first contact, evidence for particular contact period subject matter dominating in art of this region, and the oldest date yet recorded for contact art in Australia.
\end{abstract}

\section{Introduction}

Indigenous societies worldwide underwent tremendous and rapid change following contact with other societies such as British explorers and traders, Macassan trepanging crews and Christian missionaries. There is now a vast and growing literature on the nature of early contact in Australia; however, rarely have Australian contact rock art images been studied comprehensively. In 2008 a large-scale Australian Research Council-funded project titled Picturing Change: 21st Century Perspectives on Recent Australian Rock Art was initiated by Paul S.C. Taçon, Alistair Paterson, June Ross and Sally K. May to address this issue. While Picturing Change includes four key regions (Wollemi National Park in New South Wales; the Pilbara of Western Australia; Central Australia; and western/northwestern Arnhem Land), this paper focuses on preliminary results from fieldwork in Arnhem Land only and reports on the significance of these findings to this national initiative.

\section{Background}

While individual contact rock paintings and petroglyphs were noted by a number of early Australian archaeologists, ethnographers, anthropologists, explorers and artists (e.g. Mountford 1956:162, 175), it was not until the 1990s that detailed summaries and overviews of contact rock art in Australia began to appear. This included Robert Layton's (1992)

\footnotetext{
School of Archaeology and Anthropology, Research School of Humanities and the Arts, The Australian National University, Canberra, ACT 0200, Australia sally.may@anu.edu.au, u4129920@anu.edu.au

2 School of Humanities, Gold Coast Campus, Griffith University, QLD 4222, Australia p.tacon@griffith.edu.au

${ }^{3}$ Archaeology and Natural History, School of Culture, History and Language, College of Asia and the Pacific, The Australian National University, Canberra, ACT 0200, Australia daryl.wesley@anu.edu.au
}

Australian Rock Art: A New Synthesis which provided a brief and selected overview of contact rock art. Ursula Frederick (1997, 1999) is one of the few in Australia who has undertaken focused contact rock art research, concentrating on Watarrka (Kings Canyon) National Park, and with Annie Clarke, on depictions of ships on Groote Eylandt (see Clarke 1994; Clarke and Frederick 2006; Roberts 2004). As Frederick (1999:132-133) notes, contact studies remain a largely unexplored theme in Australian rock art research, yet 'the rock art of contact provides generous scope for a convergence of archaeological, anthropological and historical research designs'.

Interestingly, McNiven and Russell (2002: 32-33) note a clear focus on secular interpretations of contact rock art when it has been interpreted by previous researchers. They conclude that 'By extending a counter-reading of sketchy historical sources to include archaeological evidence such as contact rock art, we have revealed the existence of a post-contact Indigenous landscape that was regulated by ceremonial strategies and systems of place marking designed to combat European colonisation' (McNiven and Russell 2002:37; see also David and Wilson 2002:57-58).

Outside Australia there has been recent interest in contact images, with important studies particularly in southern Africa (e.g. Ouzman 2003; Ouzman and Loubser 2000; Ouzman and Smith 2004) and in North America (e.g. Keyser and Klassen 2003; Klassen 1998; Klassen et al. 2000; Molyneaux 1989). Significantly, the art of prehistoric Europeans, Indigenous Australians and other peoples of the world has always informed debates about the nature of art, culture and society, with much progress in the recognition of the existence of cave art by the scientific community occurring early in the twentieth century (Bahn and Vertut 1997:22). At the same time, Indigenous peoples entered their own forms of discourse about European encounters and the nature of the world as well, some of which have been preserved in rock art. As Molyneaux (1989:212) notes for changing depictions in Micmac rock art of eastern Canada:

As shown by the many other petroglyphs of colonial settlements, wigwam villages, churches, altar-pieces, sailing ships, and other aspects of 18th- and 19th-century life, the Micmac were observers and, from their side of the issue, participants in the changing world.

Ouzman (2003:253) continues this argument, suggesting that the Indigenous 'reverse gaze' through rock art of the contact period has the potential to inform us about a diversity of issues including expanding our understanding of ourselves. He argues in relation to Bushmen beliefs about the rock art of southern Africa:

These beliefs ... are one of the most powerful means of informing ourselves not only about Bushman society, but about nonBushmen. The irony is that the information flow is still very 
much from 'them' to 'us' but the type of information so gained is qualitatively different to the usual rock-art research because it tells us as much about who we are and, perhaps more to the point, who we are not, as it does about the rock-artists. The indigenous reverse gaze imagery is also unfettered and uncensored by the mental and iconographic constructions of the colonists (Ouzman 2003:253).

Both the Canadian and South African examples are applicable to Indigenous Australia in that they challenge Australian rock art researchers to consider the implications of the 'reverse gaze' for this continent, as well as the ways it affects our reading of contact histories.

Our own research aims to expand upon these international approaches through the consideration of Arnhem Land (and other regions') art within its wider artistic, archaeological, historical and ethnographic context. In Australia, perhaps more than anywhere else in the world, this is all possible as Indigenous people often remain connected to their rock art heritage and elements of the cultural or historical information embedded in this heritage.

Never before has there been a comprehensive study of Indigenous contact rock art from Australia. As mentioned previously, Picturing Change was established to address this shortcoming in Australian rock art research. As Layton (1992:94) suggests, 'The impact of European colonisation on rock art, and all aspects of indigenous culture, extends far beyond the mere depiction of introduced subjects'. This research project thus goes beyond previous approaches that often were limited to introduced subjects, in order to describe the creation of standard motifs and schemas, what is and is not depicted, and the possibility of symbolic meaning. With this project we also aim to illustrate the ways in which contact period rock art is still significant for Indigenous Australians in the twenty-first century and will detail contemporary stories about these important places, many of which are under threat from contemporary industrial development and natural erosion.

\section{The Study Area}

$\overline{\text { During 2008-2010, fieldwork was undertaken in northwestern }}$ Arnhem Land or, more specifically, in the Wellington Range, to document rock art. Bordered by the Arafura Sea to the north, King River to the east and the Coburg Peninsula to the northwest, this region is rich in Indigenous culture and associated cultural remains. At the request of the Aboriginal traditional owners no more specific site locations are revealed in this paper. The west and northwest Arnhem region is dominated by the Arnhem Land Plateau with much of the surrounding environmental context influenced by this major geological and geomorphological feature. The region has a diversity of environmental zones including coastal and estuarine areas, alluvial floodplains, major river systems, dissected sandy plains, steep foothills and ridges, and the plateau area itself. The landscape has been affected by significant environmental change since the Pleistocene sea-level rise and subsequent evolution of the major tidal river systems. Geologically the area is dominated by the Kombolgie sandstone subgroups of which the Mammadewerre Sandstone of the Wellington Range is one. The geology of the region in turn gives rise to the development and location of specific micro-environments such as monsoon vine forests, sedge, grass and paperbark swamps and freshwater springs.

The Wellington Range is one of the northern-most ranges in Australia and covers an area of hundreds of square kilometres. The extent of the rock art is unknown as no systematic surveys of the whole range have taken place. Some researchers, such as George Chaloupka and Daryl Wesley, have documented sites as part of their research or employment as archaeological consultants. Chaloupka (1993), in particular, included sites recorded in the Wellington Range in his stylistic chronology of western Arnhem Land rock art.

The Wellington Range covers a large area and parts of the range are 'owned' by different Indigenous cultural groups. The area of interest for this fieldwork belongs to Maung-speakers with Ronald Lamilami as senior traditional owner. Ronald Lamilami's father, Reverend Lazarus Lamilami, was a famous Arnhem Land figure and described many of his experiences, including his relationship to rock art sites in the Wellington Range, in his book Lamilami Speaks (1974):

The people of South Goulburn Island, Waruwi, and the people of North Goulburn Island, Waira, are the people we call Malalgorgoidj - Malalgoidj means island, and Malalgorgoidj means people of the island. They are Maung and I am Maung, but I come from the mainland. I come from the mainland on the west side of Goulburn Island. I was born in Ngudigin territory that is part of Manganiowal, and so I am really Manganowal like my father's people (Lamilami 1974:7).

\section{Methodology}

For our Picturing Change research we undertook an extensive survey of an isolated part of the Wellington Range. This was done in collaboration with Daryl Wesley's $\mathrm{PhD}$ research which investigates changes that have occurred in Indigenous occupation of northwestern Arnhem Land in relation to contact with the mythological Baijini, the Macassans, and Europeans. This part of Arnhem Land is well-known for its Macassan heritage and extensive research (including excavation) that was originally undertaken by Campbell Macknight (1969, 1986); rock art was not a focus of his research.

During our survey over 150 rock art sites were recorded using rapid site recording techniques. Rapid site recording involves locating rock art sites via standard foot surveys, completing a rapid site recording form (which incorporates standard archaeological site recording details such as GPS coordinates and site description as well as more detailed sections for art listing styles, techniques and other information), and photographing the site and key rock art images within the site. Three rock art complexes were then selected as case studies for Picturing Change. These site complexes are Malarrak, Djulirri and Bald Rock. Each complex consists of multiple rockshelters each in turn housing an extraordinary number of rock paintings. Rockshelters with hundreds of rock paintings are not unusual in western and northwestern Arnhem Land but the complexes we chose contain a great diversity of rock painting styles and time periods. These site complexes were selected as case studies for Picturing Change because they also included important depictions of contact between Indigenous Australians and groups from outside Australia. 


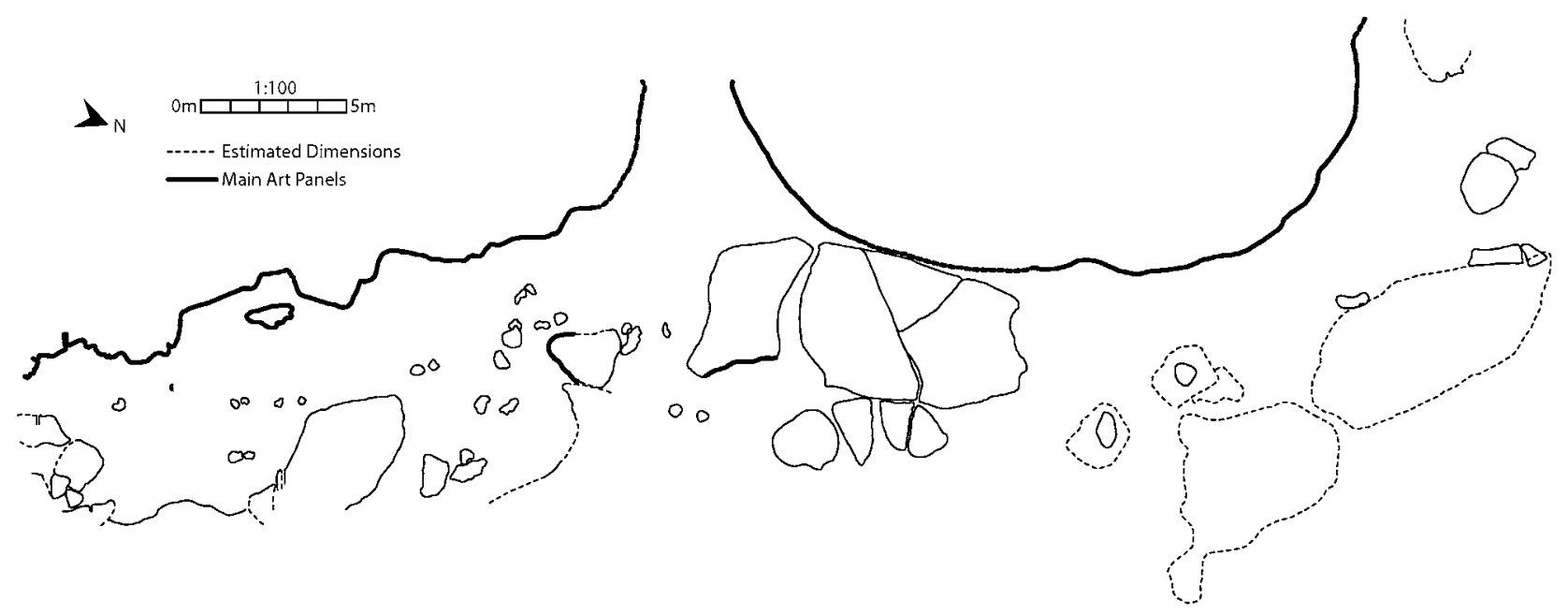

Figure 1 Djulirri main shelter, showing location of key rock art panels.

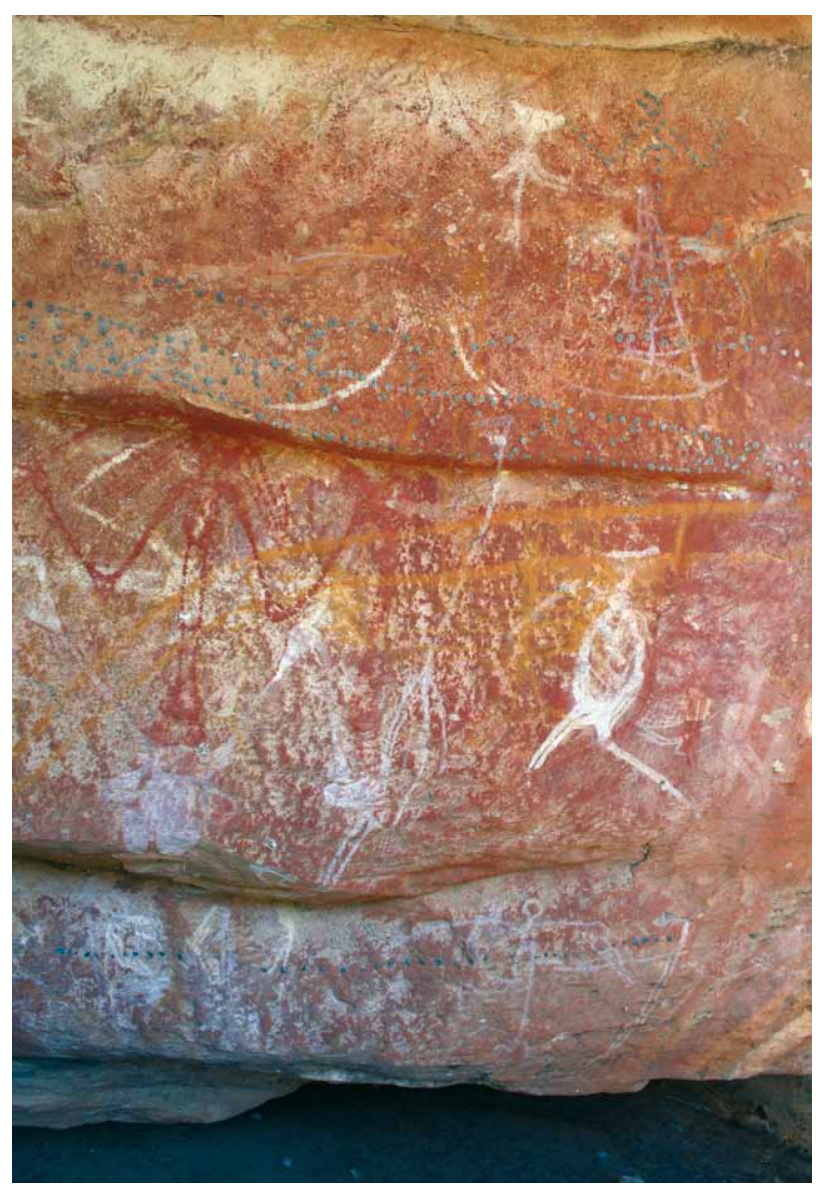

Figure 2 Panel featuring a painted prau underneath a beeswax 'snake' at Djulirri (Photograph: Sally K. May).

Malarrak, Djulirri and Bald Rock were recorded in detail during the 2008-2010 field seasons. Malarrak includes four separate rockshelters while at Djulirri the complex was so large that time permitted the recording of only three large adjoining rockshelters (rock faces, ceilings, and associated rocky outcrops) out of 55 in close proximity (see Taçon et al. 2010a, 2010b) and dozens more sites nearby. Finally, at Bald Rock a single large rockshelter was documented. At each of these shelters a full detailed inventory was made of the artworks (including descriptions, scaled and unscaled photographs and

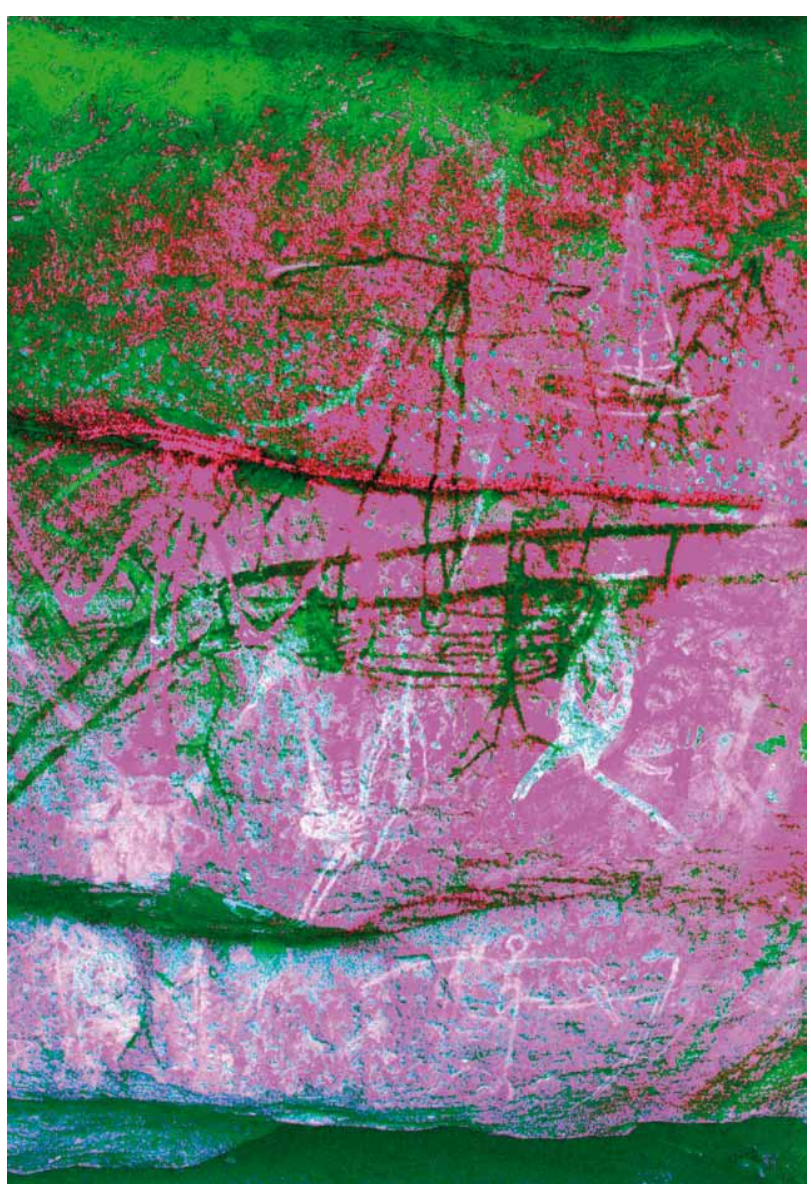

Figure 3 Digital manipulation of Figure 2 highlighting the painted prau underneath the beeswax 'snake' that was dated (see text) (Photograph: Sally K. May).

measurements for each figure). Associated archaeological evidence was recorded and excavations were undertaken in two of these shelters (Malarrak and Bald Rock). The rock art data were then put into a database for analysis. At Djulirri and Bald Rock samples were taken from beeswax art covering contact rock paintings and submitted for radiocarbon dating. The samples were chosen to provide minimum and/or maximum ages for some of the key contact rock paintings at the site. This fieldwork was undertaken in collaboration with Ronald Lamilami and his family. They accompanied us to each of the sites and allowed us 


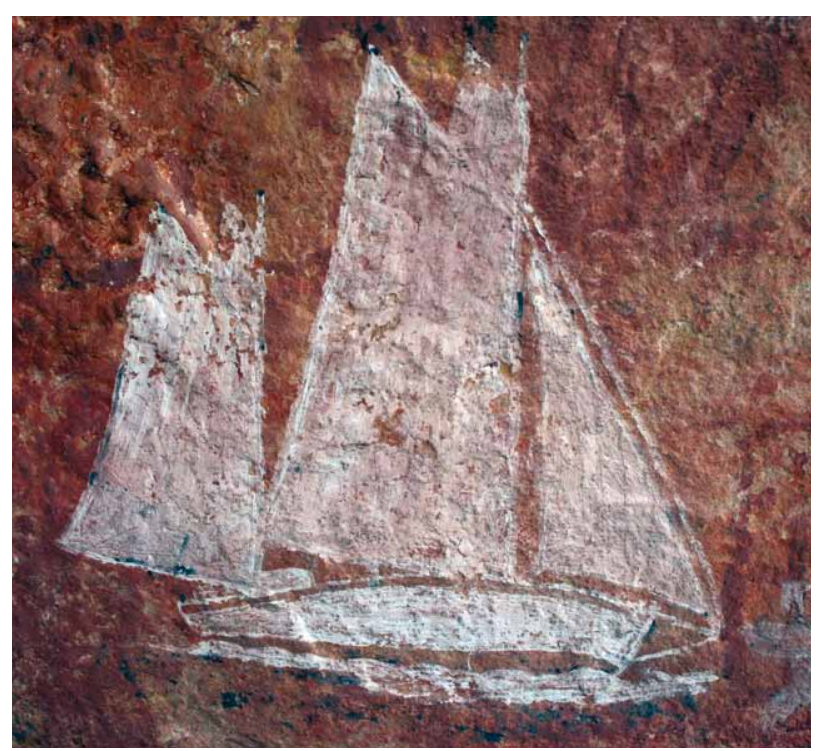

Figure 4 One of the painted sailing vessels at Djulirri (Photograph: Sally K. May).

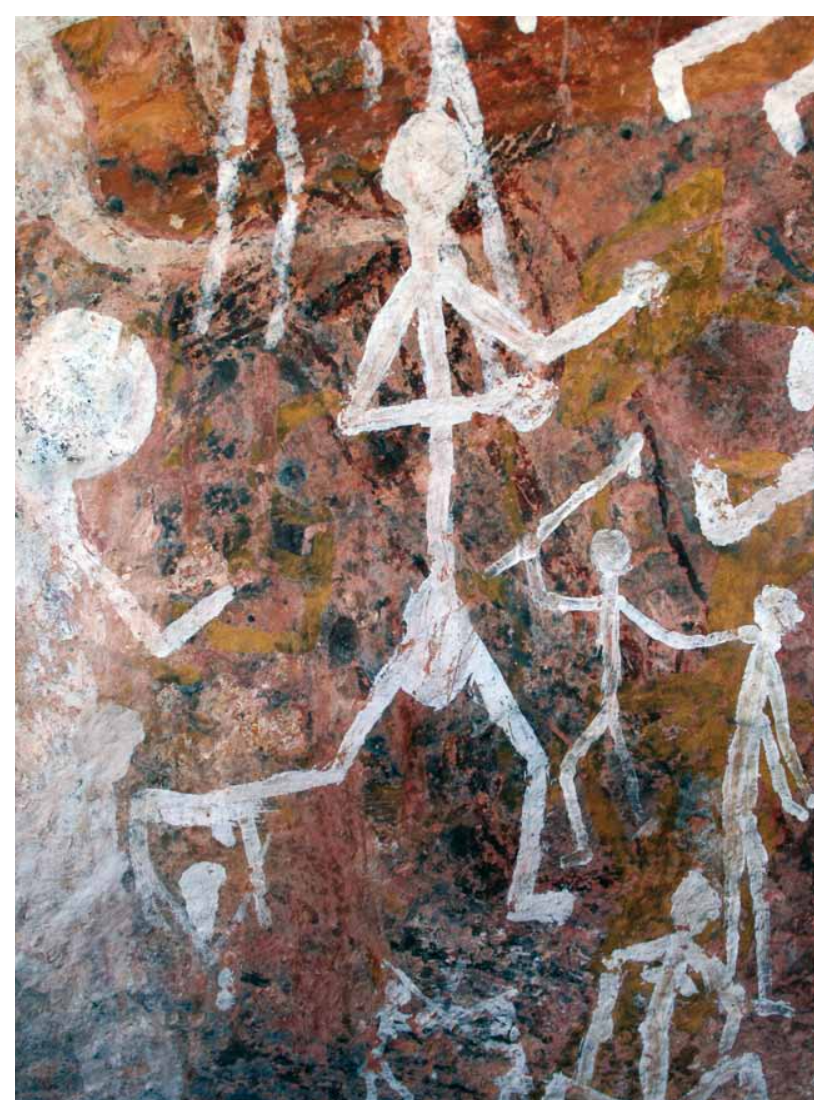

Figure 5 Human figure depicted with boxing tape or gloves, Djulirri (Photograph: Sally K. May).

to record ethnographic information relating to the region, the individual sites, and where possible, individual motifs.

\section{Results}

\section{Djulirri}

Djulirri is the Indigenous name for a series of rockshelters in the Wellington Range. The shelters adjoin each other and overlook a valley and a long network of other marked rockshelters on the other side of this valley (these shelters were documented using

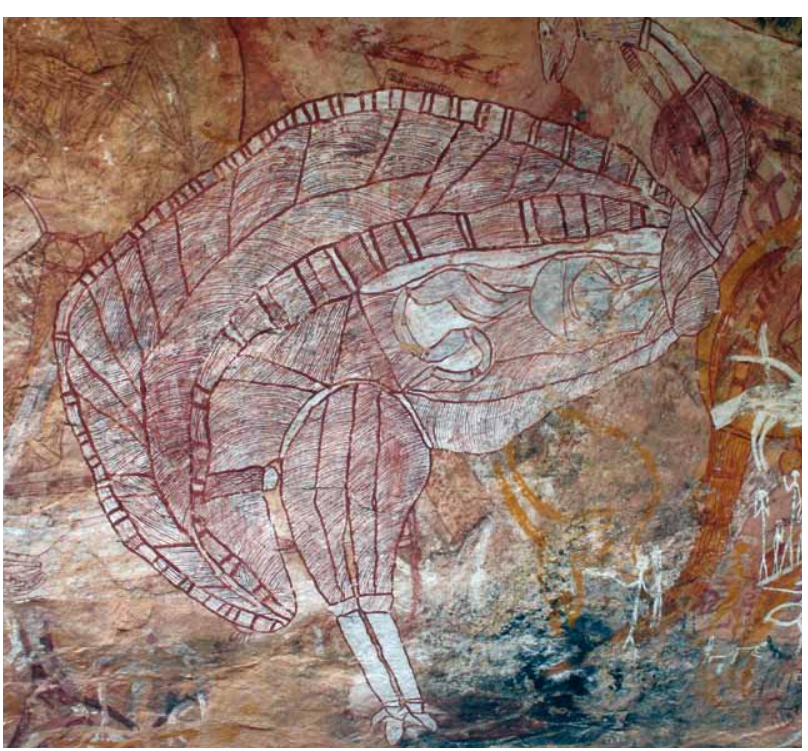

Figure $6 \mathrm{X}$-ray emu painted at Djulirri and possibly the most recent painting at the site (Photograph: Sally K. May).

rapid site recording techniques in 2009). For our case study, $55 \mathrm{~m}$ of rockshelter surface plus the ceiling of the rockshelters and the associated rocks were recorded in detail (Figure 1). While the exact number is not yet known, there are at least 20 layers of painting in sections of the rockshelter surface. We documented over 1100 individual images, including over 700 paintings, 48 beeswax figures, 68 stencils, 1 engraving and 5 prints during the 2008 field season in the area defined in Figure 1. Importantly, for this study we documented rock painting 'scenes' as individual motifs. For example, three human figures standing onboard a ship were recorded as one motif for this research. This is contrary to some standard European practices of rock art recording but was necessary in order to complete the fieldwork in a reasonable time frame. Due to our recording methods, future researchers will still be able to draw out this level of information from our database for their own research if needed.

Just as archaeologists document all artefacts recovered during an excavation we felt it appropriate to record all rock art at a site despite our focus being contact art. This allowed us to analyse contact art within its full rock art context (e.g. Table 1). It is important to note at this point that thousands of other rock paintings and beeswax figures surrounding the rockshelters were recorded in detail. Djulirri, as a complex of sites, has an extraordinary number of painted shelters and further research is necessary to document these sites in detail.

At Djulirri, introduced subject matter begins before AD 1664 with the depiction of a yellow painted Macassan prau (SSAMS ANU-6813). This is the oldest date yet for contact art in Australia (see Taçon et al. 2010b). This prau (Figures 2-3) is painted beneath a beeswax 'snake' that we were able to sample and for which we obtained a radiocarbon date, hence, providing us with a minimum age. Many hundreds of paintings were produced at Djulirri after this date. This in itself is an important finding of this research - art was being produced in abundance throughout the contact period, finishing approximately 50 years ago. While introduced subject matter is easy to interpret at Djulirri, contact paintings depicting more traditional subject matter can only be 
identified through their rock art context (i.e. paintings of $\mathrm{x}$-ray kangaroos over the top of a painted European sailing ship).

Other contact rock paintings at Djulirri include 20 introduced watercraft (e.g. Figures 2-4), a bicycle, a four-wheeled horse drawn buggy (without any horses), fighters apparently wearing boxing gloves or tape (Figure 5), letters from the English Alphabet, Ngalyod (the Rainbow Serpent), and kangaroos and emus depicted in $\mathrm{x}$-ray form (Table 2). It has been determined that the most recent painting at Djulirri is probably a depiction of an emu with white solid background and red single-line infill, a painting with brushwork similarities to the work of a recently deceased Indigenous artist now known as Wamud Namok (Figure 6) (see also Brody 1984; West 1995).

\section{Malarrak}

Malarrak is a site complex approximately $10 \mathrm{~km}$ from Djulirri and is the most accessible of any of the sites we documented. Four rockshelters within this complex were recorded in detail during our 2008 and 2010 field seasons. These were not adjoining shelters (as for many of the sites at Djulirri) but were all within a $1 \mathrm{~km}$ radius. The largest of the Malarrak rockshelters contains 232 paintings, 8 stencils, and 17 identified layers of rock art (Figures 7-8). The oldest

Table 1 Overview of subject matter depicted at Bald Rock and Malarrak. It highlights the percentage of paintings, drawings, stencils and engravings (writing) that depict introduced subject matter. Beeswax motifs have been excluded.

\begin{tabular}{|c|c|c|c|c|}
\hline \multirow[t]{2}{*}{ Subject Matter } & \multicolumn{2}{|c|}{$\begin{array}{l}\text { Bald Rock } \\
\text { (WR142) }\end{array}$} & \multicolumn{2}{|c|}{$\begin{array}{c}\text { Malarrak } \\
\text { (WR011, WR012, WR013, WR014) }\end{array}$} \\
\hline & $\#$ & $\%$ & $\#$ & $\%$ \\
\hline Artefact & 3 & 0.52 & 1 & 0.27 \\
\hline Bird & 10 & 1.73 & 10 & 2.67 \\
\hline Composite Being & 0 & 0 & 2 & 0.53 \\
\hline Fish & 27 & 4.67 & 52 & 13.90 \\
\hline Other Marine & 4 & 0.69 & 3 & 0.80 \\
\hline Geometric & 64 & 11.07 & 75 & 20.05 \\
\hline Human & 233 & 40.31 & 119 & 31.82 \\
\hline Land Mammal & 28 & 4.84 & 18 & 4.81 \\
\hline Plant & 0 & 0 & 2 & 0.53 \\
\hline Reptile & 18 & 3.11 & 24 & 6.42 \\
\hline Unknown & 181 & 31.31 & 33 & 8.82 \\
\hline Introduced Subject Matter & 10 & 1.73 & 35 & 9.36 \\
\hline Total & 578 & 100.00 & 374 & 100.00 \\
\hline
\end{tabular}

Table 2 Summary of introduced subject matter depicted at Bald Rock, Malarrak and Djulirri. Note that the numbers for Djulirri may increase in the future as further technical analysis of photographs takes place.

\begin{tabular}{|c|c|c|c|}
\hline Introduced Subject Matter & $\begin{array}{l}\text { Bald Rock } \\
\text { (WR 142) }\end{array}$ & $\begin{array}{c}\text { Malarrak } \\
\text { (WR011, WR012, } \\
\text { WR013, WR014) }\end{array}$ & $\begin{array}{l}\text { Djulirri } \\
\text { (WR057) }\end{array}$ \\
\hline Aeroplane & 2 & 0 & 1 \\
\hline Bicycle & 0 & 0 & 1 \\
\hline Building & 0 & 1 & 0 \\
\hline Can & 0 & 0 & 1 \\
\hline Coffee Mug & 0 & 1 & 0 \\
\hline Gun & 0 & 3 & 3 \\
\hline Four-Wheeled Horse-Drawn Buggy & 0 & 0 & 1 \\
\hline Horned Animal & 0 & 4 & 2 \\
\hline Knife & 2 & 1 & 0 \\
\hline $\begin{array}{l}\text { Human (in contact pose with moustache and/or with } \\
\text { introduced accessories) }\end{array}$ & 0 & 1 & 15 \\
\hline Row Boat with Harpoon & 0 & 0 & 3 \\
\hline Sailing Vessel - European & 1 & 18 & 20 \\
\hline Sailing Vessel - Prau & 0 & 1 & 2 \\
\hline Smoking Pipe & 0 & 2 & 0 \\
\hline Tobacco Pouch & 0 & 1 & 0 \\
\hline Tobacco Tin & 3 & 0 & 0 \\
\hline Unidentified & 0 & 2 & 1 \\
\hline Writing (English letters or numbers) & 2 & 0 & 4 \\
\hline Total & 10 & 35 & 54 \\
\hline
\end{tabular}




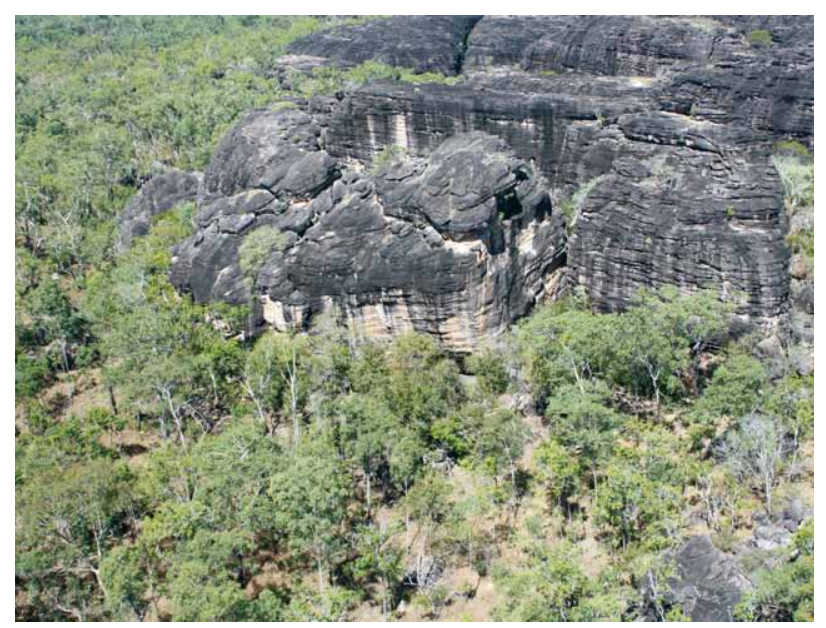

Figure 7 Aerial photograph of the Malarrak complex (Photograph: Daryl Wesley).

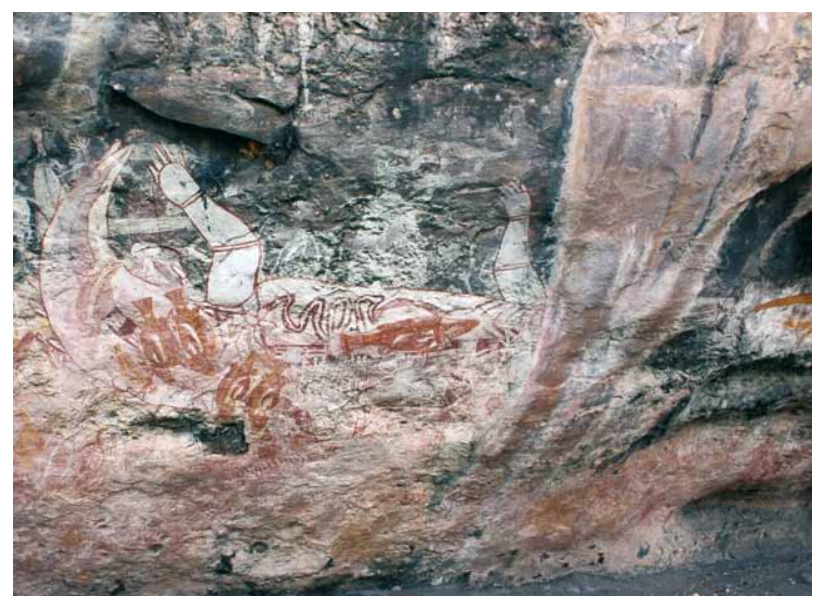

Figure 8 The main shelter at Malarrak (Photograph: Paul S.C. Taçon).

surviving paintings appear to be a series of human female figures painted in red and white (Figure 9) as well as a goanna and fork-tail catfish (Arius leptaspis) with finely-painted infill. The most recent paintings are a series of large red, white, yellow and red barramundi (Lates calcarifer). The largest shelter within the Malarrak complex is also home to paintings of introduced subject matter. These include a metal knife with sheath, a coffee mug, and a prau (Table 2).

The three remaining recorded shelters at Malarrak contain (a) 33 paintings, (b) 62 paintings and 2 beeswax figures and, (c) 33 paintings and 6 stencils. Natural deterioration and damage from feral animals has caused significant damage to two of these four shelters. Contact rock art is found at each shelter and includes sailing vessels, a house-like structure, introduced animals (goats) and guns.

\section{Bald Rock}

The last of our three case studies is generally known as 'Bald Rock' (Figure 10). The Indigenous name for the larger area is Maliwawa. As with Djulirri and Malarrak, Bald Rock is a complex of rockshelters each with abundant rock paintings. We decided to record one of the largest rockshelters in the area, and also the one with evidence from the contact period. This site was recorded during our 2009 field season and is c.8.5km from Malarrak. This main shelter at Bald Rock contains 542 paintings, 76 beeswax figures (some of which were single pellets of beeswax), 31 stencils, 3 drawings, 1 print and 1 engraving.

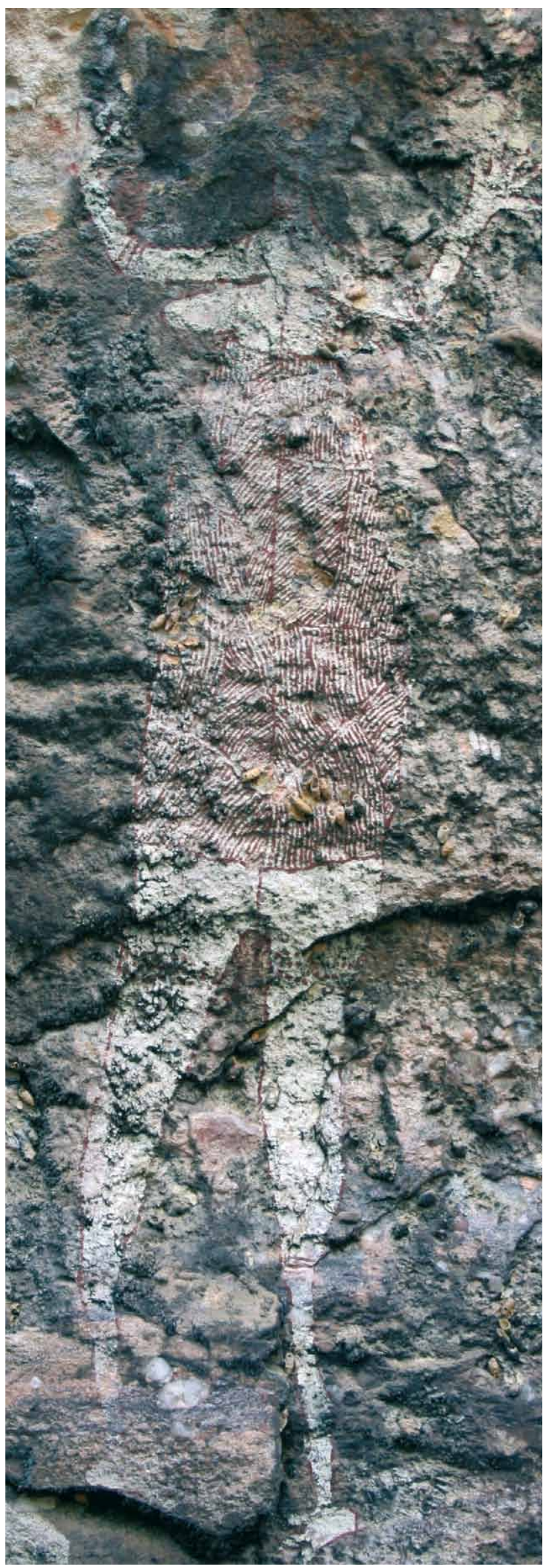

Figure 9 One of a series of human female figures painted in red and white and thought to be the oldest paintings at Malarrak (Photograph: Sally K. May). 


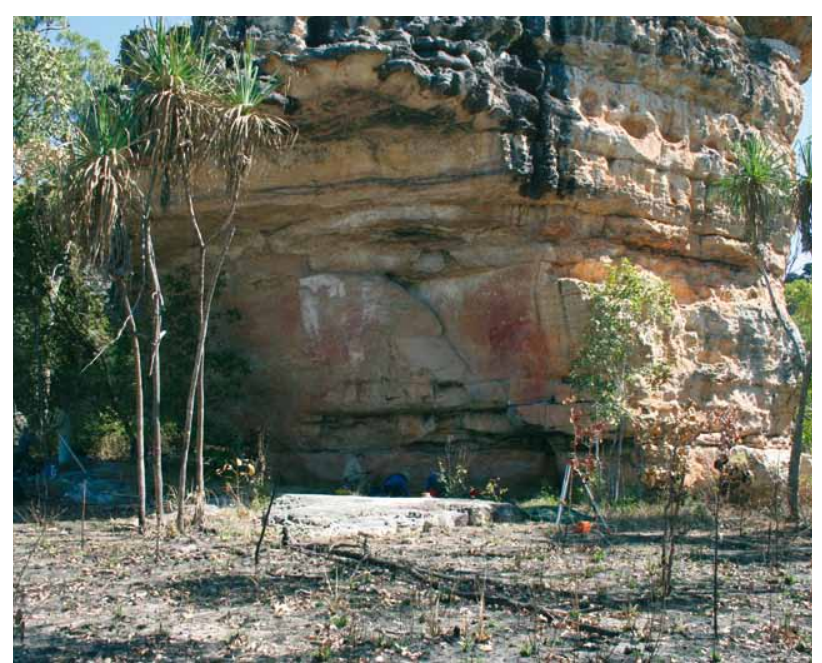

Figure 10 The main shelter at Bald Rock (Photograph: Sally K. May).

Bald Rock contains 5 stencils, 3 paintings, 1 engraving and 1 drawing featuring introduced subject matter. This includes two English words - one of these words is drawn with charcoal and is in cursive handwriting. The other is scratched into the surface of the shelter and spells what we suspect is a person's name, Noreman. Three circular stencils, the same size as a typical tobacco tin used widely in Australia throughout the early 1900s, are found at this shelter along with two stencils of large knives. There is one painted boat (an ocean cruiser), one aeroplane (Figure 11) and a possible bi-plane (as also depicted at Djulirri) (Table 2).

\section{Discussion}

There are many intriguing facts that emerge from the data presented here. The first is that, while contact rock art appears from the very earliest contact encounters, it does not replace more traditional rock art styles and subject matter. We know this thanks to detailed recording of the sites and the establishment of a chronology based on superimposition of motifs. In fact, the most recent paintings at all of the sites recorded depict classic Arnhem Land subjects such as fish, macropods and emus in 'precontact' styles. It is as though the local artists were noting and commenting upon the introduced aspects of the visiting cultures and then simply returning to their more usual artistic activities. We can confidently say that rock art continued to play a cultural and educational role in these societies long after first contact with non-Indigenous groups.

One of the most interesting aspects of the contact imagery painted at these sites is how the artists used traditional artistic protocols for these new subjects. For example, the artists have repeatedly depicted sailing vessels with full sails, anchors deployed and rudders. Sometimes, crew, cargo and other objects are illustrated. Artists are choosing to highlight the key features of the vessels, just as they highlight the key features when they paint a macropod with internal organs visible ( $\mathrm{x}$-ray), even though we would never actually see ships at anchor and in full sail at the same time, or be able to see the rudder and keel below the surface of the water. This is important evidence for the continuation of design conventions across time and subject matter.

From the more than 150 rock art sites documented during our 2008-2010 field seasons, only a small number contained

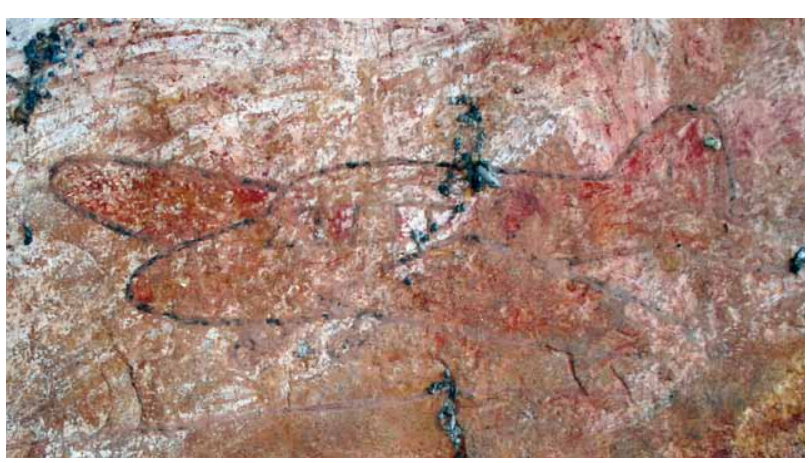

Figure 11 An aeroplane painted at Bald Rock (Photograph: Sally K. May).

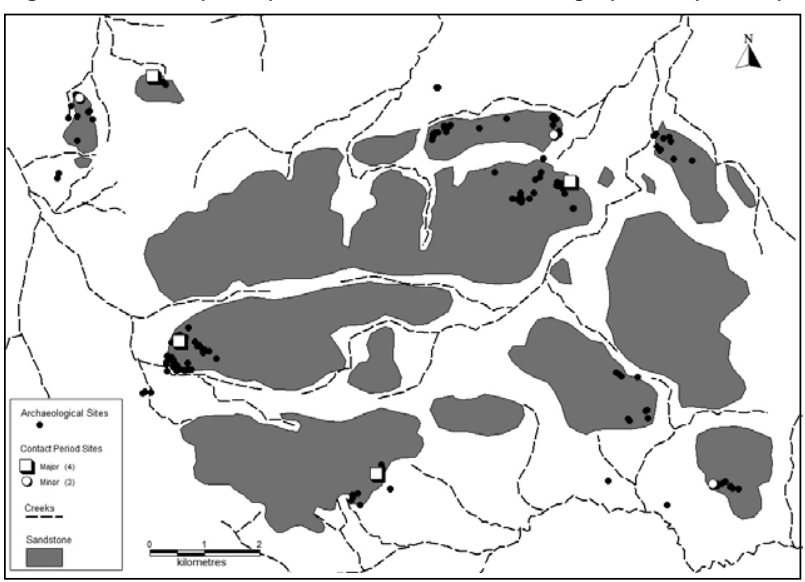

Figure 12 General distribution of all archaeological sites documented in 2008-2010 field seasons. It highlights the major and minor contact rock art sites within the study area. Locations have been deliberately generalised to protect the location of the sites.

paintings that were known to be from the contact period (i.e. that depicted introduced subject matter) (see Figure 12 for a preliminary overview of the sites). This is important as it may reveal something of the movement of people through the landscape in the contact period. Did contact with Macassan traders and, later, with British explorers and settlers impact upon traditional movement of people through the landscape? If contact rock art featuring introduced subject matter is an accurate indicator of this movement then our research suggests that a change is occurring at this time. For example, during the contact period, there is an intensification of occupation at the three major site complexes discussed in this paper and a general trend of limiting occupation and the painting of rock art throughout the rest of this part of the Wellington Range. However, one problem with this argument is that our research has demonstrated that much contact art is 'undetectable' unless it is shown in relation to introduced subject matter or dated to the contact period. In other parts of the range detailed analyses will be needed before the full picture about the importance of particular complexes such as Djulirri, Malarrak and Bald Rock is known.

To expand upon this idea further it is worth considering the wider archaeological context of this study. During 2008 and 2009, 273 Indigenous archaeological sites (consisting of rock art, rockshelters, artefact scatters, scarred trees, stone quarries, shell middens, and shell scatters) were recorded in the region. This includes new dates for the earliest evidence for Indigenous occupation of the Wellington Range at $31,620 \pm 350 \mathrm{BP}$ (R32137/3) and evidence of occupation until at least the 1960s. 
Our wider research in the Wellington Range and the associated coastal region also shows a significant reorganisation of local residential mobility strategies over the last 250 years which can be compared against a backdrop of 31,000 years of occupation. This residential mobility is reflected in the occupation of rockshelters as well as the distribution of pre- and post-contact rock art. We would argue that a significant shift occurred to take advantage of the new economy and restructured Indigenous land-use in a way that strengthened traditional practices but also created new social capital. For instance, participation in the trepang industry required a major shift of time commitments and labour distribution by Indigenous communities that would have normally concentrated on other traditional undertakings.

The wider archaeological context always reveals a major departure from the occupation of many sites to occupation of just a few strategic sites in the Wellington Range. Within a short period of time, probably during the late AD 1600s (as evidenced by the placement of a beeswax figure dating before AD 1664 over a painting of a prau at Djulirri), Indigenous groups had significantly changed their residential mobility patterns. We argue that the contraction of residential mobility probably occurs for several reasons including:

- To carefully control access to Macassans and corridors of movement.

- To be situated at locations best suited for meeting with other Aboriginal groups to facilitate trade and exchange and other traditional commitments.

- To control the flow of items into the traditional economy.

- To introduce new technologies and materials (such as glass, metal etc) to improve the ability to extract more resources from local environments which, in turn, sustain longer periods of occupation and larger groups at these nodes.

The changes probably took place very rapidly in response to contact and resulting participation in the trepang industry. Indigenous life after Macassan contact would have begun with a period of instability as Indigenous communities reorganised themselves and their worldview to take into account the new opportunities and situations presented to them. Out of this a modified social and economic order would have been developed incorporating the new social capital being generated from participation in the Macassan trepang industry, thus strengthening traditional lifeways and practices rather than diminishing them. Indigenous control of access and negotiation in the trepang industry was probably a unique circumstance in recent Australian history.

The archaeological evidence suggests that the technologies and customs that were sought after and acquired from Macassans were those that would benefit and strengthen traditional customs and practices. In more recent times a similar approach can be seen in the development of hybrid economies where Indigenous communities have embraced modes of participation, for example, Indigenous ranger programmes, as a way of being able to maintain and strengthen traditional customs and practices.

The complexes of rock art recorded for this research highlight key locations for this new movement across the landscape. This includes places located between the sites of contact with Macassans, missionaries and others. Paddy Cahill's station at
Oenpelli (later the CMS Anglican Mission), the Goulburn Island Methodist mission, and Macassan trepang processing sites are just some of the places that were of concern to local people sites to which they often journeyed for visits, to trade or just to observe. For example, Esther Manakgu recalls that as a child (in the 1920s) her father heard about a settlement at Oenpelli and journeyed there himself to 'see what was going on'. He later returned to collect his family and take them to the settlement to 'see for themselves' (May 2008). This issue of shifting movement in the contact period is an exciting area of ongoing research that links rock art with archaeological excavation and local Indigenous histories.

\section{Conclusions}

One of the key aims for Picturing Change is to explore the nature of contact through rock art. What then do the Malarrak, Djulirri and Bald Rock art complexes tell us about the contact period in northwestern Arnhem Land? Research to date emphasises three key points. The first is that traditional protocols for rock art continued long after first contact. This in itself attests to the strength of these cultural traditions. The second point is that when compared to the other areas of interest for our study (Wollemi National Park, the Pilbara region, and Central Australia) there is a particularly large concentration of contact rock paintings depicting introduced subject matter in this region. Yet much of the contact art at the three complexes documented in the Wellington Range is painted in 'pre-contact' styles and depicts traditional subject matter.

Finally, by documenting these sites we can start to understand the shifting movements of people through the landscape as a result of contact. We have just scratched the surface of the information that contact rock art can tell us about these periods of time. In 2008 senior traditional owner Ronald Lamilami explained to us that these rock art sites were like his people's history books. His generosity in sharing these books with us will help wider Australia understand this shared history and give greater voice to Indigenous perceptions of this important time period.

\section{Acknowledgements}

We thank Ronald Lamilami and his family for their support, guidance and enthusiasm throughout fieldwork in 2008, 2009 and 2010. Picturing Change is funded by ARC Discovery Grant DP0877463 and we acknowledge June Ross and Alistair Paterson as fellow Chief Investigators on this project. Much of our fieldwork in the Wellington Range has been undertaken in conjunction with Sue O'Connor and Daryl Wesley's ARCfunded project (LP0882985) 'Baijini, Macassans, Balanda, and Bininj: Defining the Indigenous Past of Arnhem Land through Culture Contact'. Many of the ideas for this paper were developed during conversations around the camp fire and we thank the many volunteers who assisted us in recording rock art complexes in 2008, 2009 and 2010. While we cannot name everyone we would like to highlight the contributions of Melissa Johnson, Ines Domingo Sanz, Janet and Phil Davill, Wayne Brennan, Kirsten Brett and Michelle Langley who spent weeks at these sites helping to produce a detailed recording of each and every painting. Stewart Fallon has been undertaking the radiocarbon dating of beeswax samples from these sites and we thank him 
for his collaboration. Finally we would like to acknowledge our own institutions, the Australian National University and Griffith University, for their support of our rock art research.

\section{References}

Bahn, P.G. and J.Vertut 1997 Journey through the Ice Age. London: Weidenfeld and Nicholson.

Brody,A. 1984 Kunwinjku Bim: Western Arnhem Land Paintings from the Collection of the Aboriginal Arts Board. Melbourne: National Gallery of Victoria.

Chaloupka, G. 1993 Journey in Time: The 50,000-year Story of the Australian Aboriginal Rock Art of Arnhem Land. Chatswood: Reed.

Clarke, A. 1994 Winds of Change: An Archaeology of Contact in the Groote Eylandt Archipelago, Northern Australia. Unpublished PhD thesis, Australian National University, Canberra.

Clarke, A. and U. Frederick 2006 Closing the distance: Interpreting cross-cultural engagements through indigenous rock art. In I. Lilley (ed.), Archaeology of Oceania: Australia and the Pacific Islands, pp.116-133. Oxford: Blackwell Publishing.

David, B. and M. Wilson 2002 Spaces of resistance: Graffiti and indigenous place markings in the early European contact period of northern Australia. In B. David and M. Wilson (eds), Inscribed landscapes: Marking and Making Place, pp.42-60. Honolulu: University of Hawai'i Press.

Frederick, U. 1997 Drawing in Differences: Changing Social Contexts of Rock Art Production in Watarrka (Kings Canyon) National Park, Central Australia. Unpublished PhD thesis, Australian National University, Canberra.

Frederick, U. 1999 At the centre of it all: Constructing contact through the rock art of Watarrka National Park, central Australia. Archaeology in Oceania 34(3):132-144.

Keyser, J.D. and M. Klassen 2003 Every detail counts: More additions to the Plains biographic rock art lexicon. Plains Anthropologist 48(184):7-20.

Klassen, M. 1998 Icon and narrative in transition: Contact-period rock-art at Writing-On-Stone, southern Alberta, Canada. In C. Chippindale and P.S.C. Taçon (eds), The Archaeology of Rock-Art, pp.42-72. Cambridge: Cambridge University Press.

Klassen, M., J.D. Keyser and L. Loendorf 2000 Bird Rattle's petroglyphs at Writing-On-Stone: Continuity in the biographic rock art tradition. Plains Anthropologist 45(172):189-201.
Lamilami, L. 1974 Lamilami Speaks. Sydney: Ure Smith.

Layton, R. 1992 Australian Rock Art: A New Synthesis. Cambridge: Cambridge University Press.

Macknight, C.C. 1969 The Macassans: A Study of the Early Trepang Industry along the Northern Territory Coast. Unpublished PhD thesis, Australian National University, Canberra.

MacKnight, C.C. 1986 Macassans and the Aboriginal past. Archaeology in Oceania 21:69-75.

May, S.K. 2008 Esther Manakgu Oral History [Video]. Kunwinjku Language Project. McNiven, I.J. and L. Russell 2002 Ritual response: Place marking and the colonial frontier in Australia. In B. David and M. Wilson (eds), Inscribed Landscapes: Marking and Making Place, pp.27-41. Honolulu: University of Hawai'i Press.

Molyneaux, B. 1989 Post-contact Micmac rock art. In H. Morphy (ed.), Animals into Art, pp.193-214. London: Unwin Hyman.

Mountford, C.P.(ed.) 1956 Records of the American-Australian Scientific Expedition to Arnhem Land 1: Art, Myth and Symbolism. Melbourne: Melbourne University Press.

Ouzman, S. 2003 Indigenous images of a colonial exotic: Imaginings from Bushmen southern Africa. Before Farming 1(6):239-256.

Ouzman, S. and J. Loubser 2000 Art of the apocalypse: Southern Africa's Bushmen left the agony of their end time on rock walls. Discovering Archaeology November/December:38-44.

Ouzman, S. and B. Smith 2004 Taking stock: Identifying Khoekhoen herder rock art in southern Africa. Current Anthropology 45(4):499-526.

Roberts, D. 2004 Nautical themes in the Aboriginal rock paintings of Mount Borradaile, western Arnhem Land. The Great Circle 26(1):19-50.

Taçon, P.S.C., M. Langley, S.K. May, R. Lamilami, W. Brennan and D. Guse 2010a Ancient bird stencils discovered in Arnhem Land, Northern Territory, Australia. Antiquity 84:416-427.

Taçon, P.S.C., S.K. May, S.J. Fallon, M. Travers, D. Wesley and R. Lamilami $2010 \mathrm{~b}$ A minimum age for early depictions of Southeast Asian praus in the rock art of Arnhem Land, Northern Territory. Australian Archaeology 71:1-10.

West, M. (ed.) 1995 Rainbow Sugarbag and Moon, Two Artists of the Stone Country: Bardayal Nadjamerrek and Mick Kubarkku. Darwin: Museum and Art Gallery of the Northern Territory. 